\title{
Enterprise Modeling for Business and IT Alignment - A Framework and Recommendations
}

\author{
Julia Kaidalova ${ }^{1,2^{*}}$, Ulf Seigerroth ${ }^{1^{*}}$ and Anne Persson ${ }^{2^{*}}$ \\ ${ }^{1}$ School of Engineering, Jönköping University, P.O. Box 1026, 55111 Jönköping, \\ Sweden \\ ${ }^{2}$ University of Skövde, School of Informatics, Högskolevägen Box 408, 54128 \\ Skövde, Sweden \\ julia.kaidalova@ju.se, \\ ulf.seigerroth@ju.se, anne.persson@his.se
}

\begin{abstract}
Eliminating the gap between business and IT within an enterprise, i.e., solving the problem of Business and IT Alignment (BITA), requires an instrument for the multidimensional analysis of an enterprise. Enterprise Modeling (EM) is a practice that supports such analysis and therefore can be used to facilitate BITA. EM serves as a tool that can capture, visualize and analyze different aspects of enterprises. This article presents a framework that describes the role of EM in the context of BITA and presents recommendations in EM for BITA.

Keywords: Business and IT Alignment, Enterprise Modeling, Enterprise Modeling Challenges, Enterprise Modeling Recommendations, Best Practice.
\end{abstract}

\section{Introduction}

The rapid development of information technology (IT) has opened up new and innovative ways for enterprises to redesign their practice. Today, IT opportunities are often used to rethink the way enterprises organize their business processes, how they communicate with their customers, and the means by which they deliver their services [1]. However, while it is undeniable that suitable IT solutions are required in order to reach organizational goals, effectively supporting business operations with appropriate IT solutions is a complicated process, due to the dynamic nature and intertwined relationship between business operations and IT solutions [2]. Current research recognizes many dimensions of business and IT alignment (BITA) [3].

BITA includes a number of dimensions, of which particularly the strategic, structural, social and cultural are identified in [4]. The strategic dimension refers to the degree to which the business strategy and plans, and the IT strategy and plans, complement each other. The structural dimension refers to the degree of structural fit between IT and the business that is influenced by

\footnotetext{
* Corresponding authors

(C) 2017 Julia Kaidalova et al. This is an open access article licensed under the Creative Commons Attribution License (http://creativecommons.org/licenses/by/4.0).

Reference: J. Kaidalova, U. Seigerroth and A. Persson, "Enterprise Modeling for Business and IT Alignment - a framework and recommendations," Complex Systems Informatics and Modeling Quarterly, CSIMQ, Issue no. 12, pp. 66-85, 2017. Available: https://doi.org/10.7250/csimq.2017-12.04

Additional information. Author's ORCID iD: J. Kaidalova - orcid.org/0000-0002-9507-0647, U. Seigerroth - orcid.org/00000002-5881-0669 and A. Persson - orcid.org/0000-0003-0740-4123. Article PII S225599221700071X. Article received: 2017 March 24. Last revision received: 2017 September 29. Accepted: 2017 October 9. Available online: 2017 October 31.
} 
the location of IT decision-making rights, reporting relationships, decentralization of IT, and the deployment of IT personnel, which is closely related to governance structures. The social dimension refers to how much the business and IT executives within an organizational unit understand and how committed they are to the business and IT mission, objectives, and plans. The cultural dimension refers to the necessity of IT planning to be aligned with cultural elements, such as the style of business planning and top management communication. Out of these, it is the strategic dimension that currently receives significantly more attention [4]. However, both strategic alignment and structural alignment influence organizational performance. In addition, BITA is closely linked to many of the social and cultural aspects of an organization. Improving alignment within these four dimensions thus enables the increase of information system (IS) effectiveness and efficiency, the enhancement of business and IT flexibility, the improvement of business performance, and other positive effects [5], [3].

The various aspects of an enterprise include organizational structure, business processes, information systems, and infrastructure, which together form an Enterprise Architecture (EA) [6]. In relation to these aspects, Enterprise Modeling (EM) is recognized as a useful practice that can provide a coherent description of various components of the EA and enable communication among stakeholders [6]. In particular, EM facilitates the creation of a number of integrated models which capture and represent different aspects (focal areas) of an enterprise [7], [8]. The essential ability of enterprise models to represent an enterprise from different perspectives makes EM a suitable tool that provides a multidimensional view of an enterprise and integrates these multiple dimensions into a coherent structure [7]. These capabilities of enterprise models also provide a powerful mechanism for dealing with the strategic and structural dimensions of BITA.

In addition, EM can also provide solid support when there is a need to develop a common understanding of the current state of affairs and reach an agreement on the future vision and strategies [7], [8]. EM is applicable in the context of BITA when there is a need to consider the multiple views of stakeholders and to create a shared understanding between them [6], [9], [10]. Furthermore, EM can be used for a broad range of purposes that require consensus-driven collaboration between stakeholders and decision makers; for instance, the development of business vision and strategies, the redesign of business practice, the development of information systems support, as well as sharing knowledge about business practice or decision-making.

For any modeling project to succeed, it is crucial that the EM practitioner is competent [11], [12]. The competence of EM practitioners can be related to (1) modeling as such, particularly, the ability to model and facilitate a modeling session, and (2) managing EM projects. Managing an EM project includes various activities exemplified by the following: selecting an appropriate EM approach and tailoring it to fit the situation at hand, interviewing the domain experts involved, defining a relevant problem, defining requirements for the results, adjusting a presentation of project results and related issues related for various stakeholders, navigating between the wishes of various stakeholders while upholding the EM project goal, assessing the impact of the modeling result and the modeling process on the organization and other activities [11].

Dealing with these activities is often far from trivial, therefore, an integrated set of best practices would significantly help EM practitioners. Identifying challenges that EM practitioners face within various stages of EM projects is an important step on the way to solving them and therefore enabling BITA, which is often a goal of an EM effort. Although several studies show that EM can be used to achieve BITA [4], [7], [13], [14], [15], [16], there are, to our best knowledge, no studies that in detail describe the role of EM in relation to BITA. Thus, the research question of this work is the following: How can EM contribute to business and IT alignment?

Accordingly, the objective of this article is to present a framework, the EM-for-BITA framework, that positions EM in the context of BITA and includes challenges and recommendations related to the use of EM in the context of BITA. The framework will be able to support EM practitioners working with EM in the BITA context. 
The remainder of the article is structured in the following way: Section 2 describes the research approach. Section 3 presents the theoretical foundation that served as a basis for this research. It covers the BITA and EM domains. Section 4 introduces the EM-for-BITA framework, while Section 5 includes discussion of the generated results.

\section{Research Approach}

This Section presents a general disposition of the study, which is in line with the design science research paradigm, including the research environment and knowledge base as two main elements (Section 2.1), as well as the grounding of knowledge and the methodologies used throughout the research process (Section 2.2). It then describes a number of guidelines that have been used to carry out this research in a rigorous manner (Section 2.3).

\subsection{Design Science Research Paradigm}

Design science is used in IS research to acquire knowledge, it seeks to extend the boundaries of human and organizational capabilities by creating new and innovative artifacts [17]. Artifacts are constructs, models, methods and instantiations that are built to address unsolved problems [17]. Such artifacts should be evaluated in relation to the utility provided in solving those problems. Among four types of artifacts that design science deals with, the aim of this study was to generate a framework, i.e., a model that positions EM in the context of BITA. The developed artifact that this study focuses on is hereafter denoted as the EM-for-BITA framework.

The framework evolved in three iterations (1, 2, 3 elements in Develop and Build in Figure 1). The results from the first two iterations are presented in [18] and [19], and the final framework is presented in this article. The two key elements that this study relies upon are environment and knowledge base (Figure 1). These two terms, together with others presented in Figure 1, are fundamental elements in the design science paradigm defined in [17] and are elaborated on below, in relation to our study.

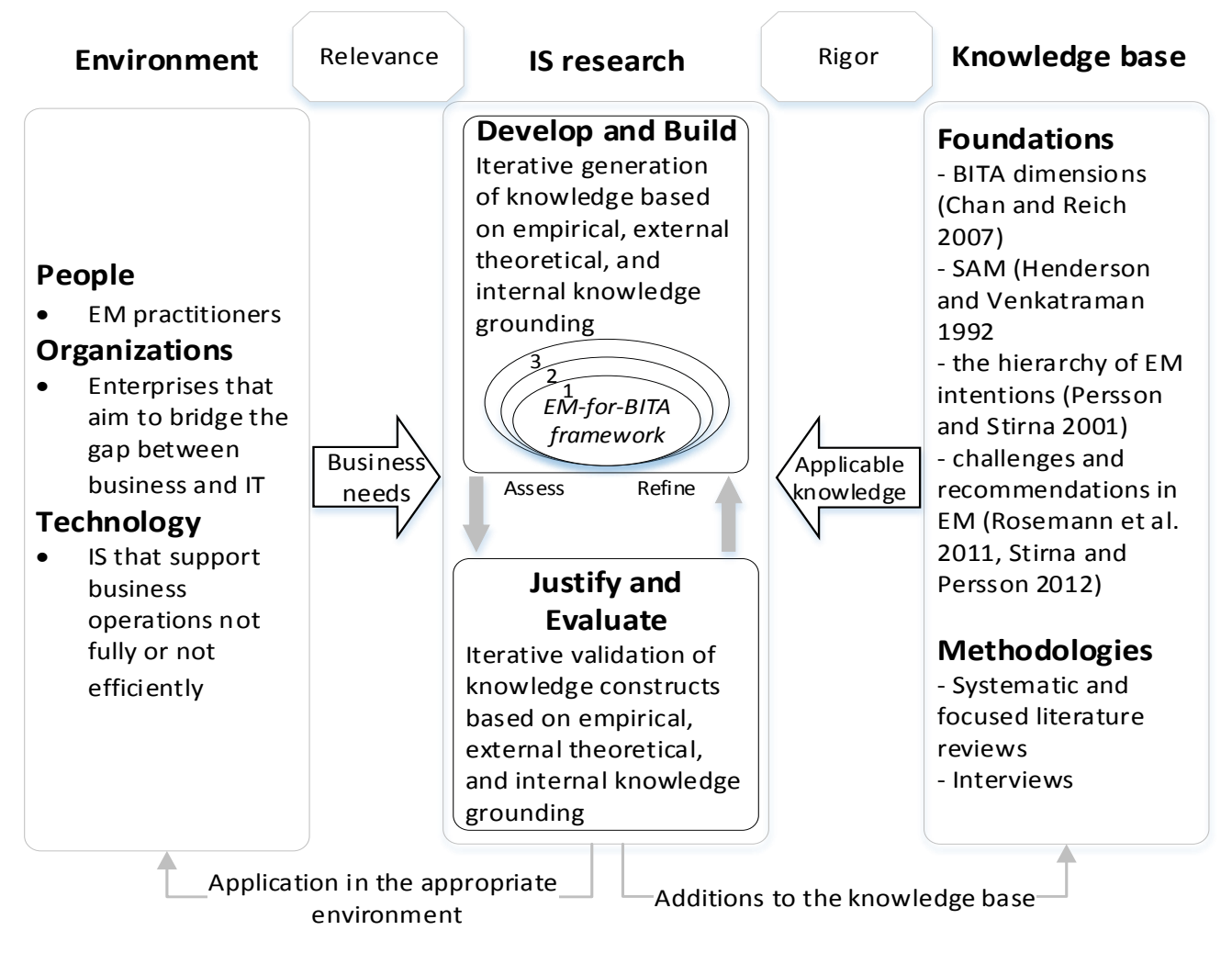

Figure 1. Information Systems Research Framework, adapted from [17] 
The need of this study is generated by the environment, and the knowledge used to carry out the study is provided by the knowledge base [17]. The environment is composed of people, organizations and technologies (existing or planned). People have different roles and capabilities within organizations. The roles that are considered within the scope of this study are EM practitioners, i.e., external consultants that carry out an EM activity as part of a knowledge sharing or business development project [20], in order to deal with one or several dimensions of a business and IT alignment problem within an enterprise. The other aspect of this research is the knowledge base, which is composed of Foundations and Methodologies. Foundations are existing theories and studies in the field, whereas Methodologies provide guidelines that can be used to Justify and Evaluate the central artifact of the study. Applying the chosen foundations and methodologies enables us to achieve rigor in research. The foundations used in this study are existing theories and studies in the EM, BITA domains and other related areas, which are described in detail in Section 3. The methodologies used during this study are systematic and focused literature reviews and interviews. The details regarding the interviews are presented in Section 2.1, and those regarding the literature reviews are included in Section 2.2.

\subsection{Research Process}

The design of the EM-for-BITA framework includes the generation of new knowledge constructs in combination with the validation of existing ones. New constructs were gradually added as the study progressed (Develop and Build), while existing constructs were validated and refined (Justify and Evaluate).

The generation and validation of knowledge constructs were supported with empirical, external theoretical, and internal knowledge grounding [21]. These three types of knowledge grounding are represented as three parallel lanes in Figure 2, each including several elements. The research process included several steps (white blocks in Figure 2) that allowed the generation and refinement of knowledge constructs (grey elements) with the EM-for-BITA framework as the final one. These steps employed literature reviews and interviews as the methodological base. Three types of knowledge grounding ensured the validity of the study.

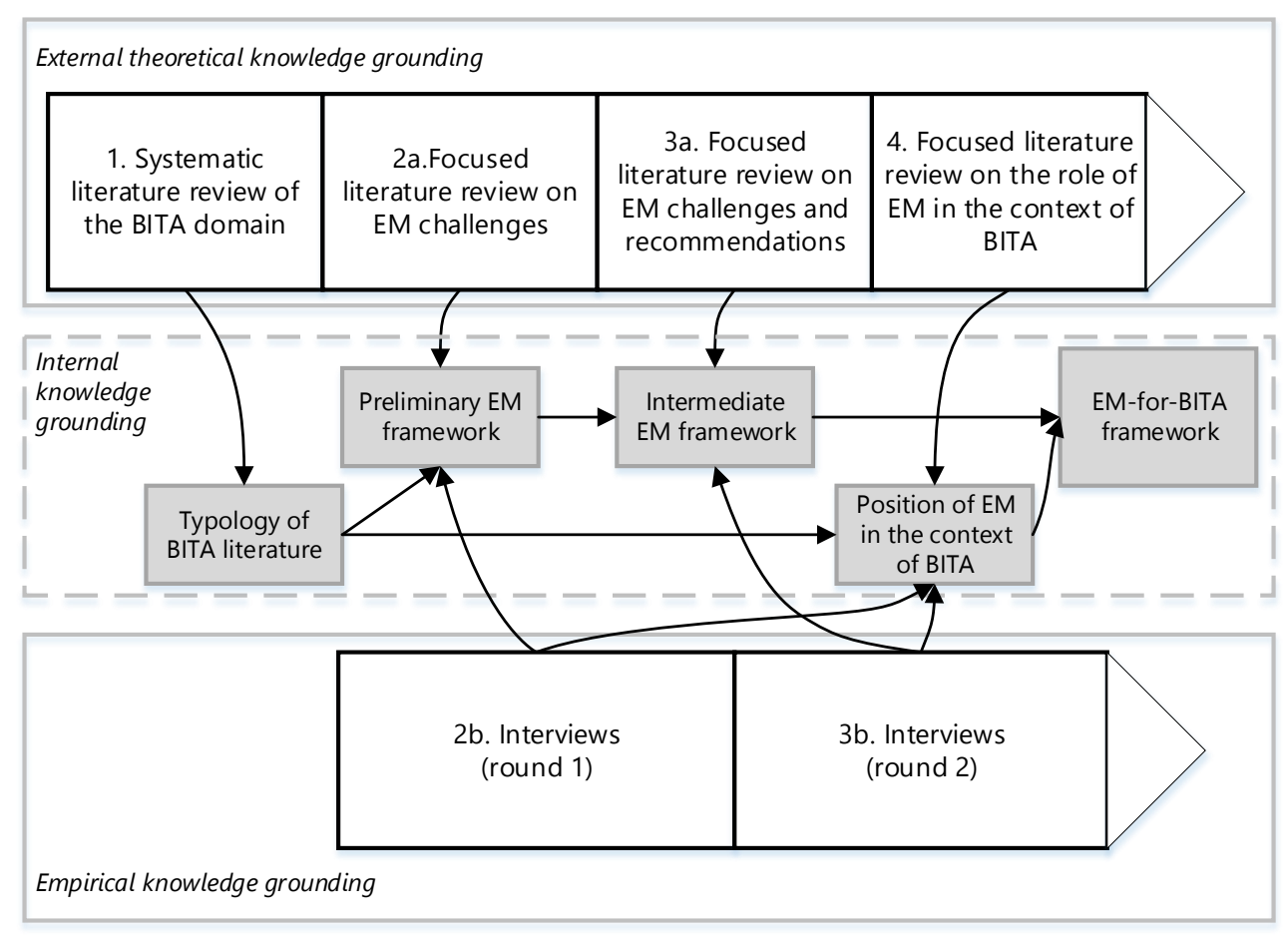

Figure 2. Research process - steps and knowledge constructs generated 
The systematic literature review (step 1) was carried out to identify the main interest areas and gaps in the BITA domain, and the role of EM in relation to BITA. The focused literature review (step 2a) was used to build a theoretical model of EM challenges, which was then validated against empirical data from the interviews (step 2b). Thereafter, a focused literature review of EM challenges and recommendations (step 3a) and the second round of interviews (step 3b) enabled the generation of the intermediate EM framework. Here the intention was to investigate EM practice, with particular attention on EM challenges and corresponding recommendations. The role of EM in the BITA domain was investigated with the help of both interview rounds (step $2 b$ and $3 b$ ), the focused literature review (step 4) and the typology of BITA literature. Finally, integrating the intermediate EM framework with the positioning of EM in the context of BITA allowed the generation of the EM-for-BITA framework.

\section{Interviews}

In total, eight semi-structured interviews were carried out in two rounds. The respondents were required to have significant experience of EM, including both managing modeling sessions and using created models for various purposes. The selected respondents had up to 35 years of EM experience acquired from numerous projects including: collaborative business development; research and development; knowledge capturing and structuring; system development; quality assurance for system development and maintenance; education for project management and requirements engineering; clarification and definition of concepts and processes; value chain analysis; business needs interpretation and analysis, and others. The respondents had various profiles and skills, with regards to the application of EM.

The interviews, which were in-depth in nature, were transcribed for thorough analysis. In addition, the collected data was analyzed incrementally after each interview, until information saturation was revealed. The respondents of the first and second interview rounds are referred to as Respondent $1-x$ and Respondent $2-x$ respectively in the remainder of the article.

\section{Literature reviews}

In order to examine the existing literature in the BITA domain, a systematic literature review was chosen as the most suitable method. Moreover, to explore EM practice in terms of challenges and recommendations, focused literature reviews were conducted to build a theoretical basis for further empirical investigations.

In this study, we followed the guidelines, presented by Kitchenham [22], to conduct the systematic reviews of the BITA domain, which included three phases: planning the review, conducting the review and reporting the review. The main aim of the systematic literature review was to discover the key areas of interest in BITA research, the gaps and trends in the domain, and to build an initial understanding of the position of EM in this domain. Two types of sources were examined: scientific databases (SpringerLink, ACM Digital Library and Emerald) and relevant workshops proceedings. We searched the aforementioned databases for papers with "Business IT alignment" in their titles, that were published from 2000 to 2012. We presumed that papers presented in the BITA and BUSITAL workshops were valid, in terms of relevance. After obtaining and outlining the set of relevant papers, it was possible to analyze the collected data - add logical tags to each paper and then create a set of categories. The results of the systematic literature review are presented in detail in [18].

In addition to the systematic literature review, three focused literature reviews were performed for this study. The aim of these focused literature reviews was to identify existing theories, related to EM challenges and recommendations, and to find existing studies that describe the role of EM in BITA. These reviews were planned and described in a transparent way [23]. Specific keywords were applied during the search: 1) enterprise modeling challenges OR enterprise modeling issues 2) enterprise modeling recommendations OR enterprise modeling guidelines 3) enterprise modeling AND business IT alignment; enterprise modeling AND alignment. Other relevant papers were found by browsing related conference and workshop proceedings, as well 
as considering the papers suggested by the authors' research network. The results of these focused literature reviews provided a theoretical basis for the generation and refinement of the framework.

\subsection{Application of Design Science Guidelines}

For this study, we also used the guidelines for design science IS research, presented in [17]. Applying these guidelines enabled us to carry out the research in a rigorous manner (see Table 1).

Table 1. Guidelines for conducting IS research [17]

\begin{tabular}{|c|c|}
\hline Guidelines & How it is addressed in this study \\
\hline $\begin{array}{l}\text { 1. Design as an artifact. This } \\
\text { guideline points out that } \\
\text { design-science research } \\
\text { must produce a viable } \\
\text { artifact in the form of a } \\
\text { construct, a model, or an } \\
\text { instantiation. }\end{array}$ & $\begin{array}{l}\text { The central artifact of this study is the EM-for-BITA framework. The } \\
\text { framework defines the position of EM in the context of BITA and provides a set } \\
\text { of challenges and recommendations when it comes to using EM for BITA. The } \\
\text { need of the framework is defined by the environment of this study, particularly, } \\
\text { EM practitioners who are dealing with BITA-related problems by using } \\
\text { participative EM (see Figure 1). The generated framework is a purposeful artifact } \\
\text { that aims to help EM practitioners apply EM in order to bridge the gap between } \\
\text { business and IT within an enterprise. }\end{array}$ \\
\hline $\begin{array}{l}\text { 2. Problem relevance. This } \\
\text { guideline concerns the } \\
\text { objective of design-science } \\
\text { research, which is to develop } \\
\text { technology-based solutions } \\
\text { for important and relevant } \\
\text { business problems. }\end{array}$ & $\begin{array}{l}\text { The EM-for-BITA framework generated in this study aims to facilitate BITA } \\
\text { achievement - a well-known issue that has remained one of the key management } \\
\text { concerns for almost three decades [24]. Several researchers have pointed out that } \\
\text { the application of EM in this context is a useful practice [13], [16], [25]. } \\
\text { However, the role of EM in the context of BITA has not been investigated } \\
\text { thoroughly, which makes this study relevant from an academic point of view. } \\
\text { There is also a clear lack of guidelines regarding the application of EM in the } \\
\text { context of BITA, which has also been pointed out during the interviews with EM } \\
\text { practitioners, conducted by the authors of this article. These factors motivate the } \\
\text { practical importance of our study. }\end{array}$ \\
\hline $\begin{array}{l}\text { 3. Design evaluation. The } \\
\text { utility, quality and efficacy } \\
\text { of a design artifact must be } \\
\text { rigorously demonstrated via } \\
\text { well-executed evaluation } \\
\text { methods. }\end{array}$ & $\begin{array}{l}\text { According to the description in Section 2.2, the knowledge in this study has } \\
\text { been validated at an empirical level, at the level of other knowledge and the level } \\
\text { of action knowledge as such. The EM-for-BITA framework has been evaluated } \\
\text { and refined iteratively using literature reviews (focused and structured) and } \\
\text { interviews. These research methodologies allowed us to gain valuable ideas and } \\
\text { insights from both theory and practice, add constructs to the existing versions of } \\
\text { the framework and therefore refine the central artifact of this study. }\end{array}$ \\
\hline $\begin{array}{l}\text { 4. Research contributions. } \\
\text { This guideline emphasizes } \\
\text { the need to provide clear and } \\
\text { verifiable contributions in } \\
\text { the areas of the design } \\
\text { artifact, design foundations, } \\
\text { and/or design } \\
\text { methodologies. }\end{array}$ & $\begin{array}{l}\text { The EM-for-BITA framework generated by this study is The Design Artifact } \\
\text { that aims to solve an actual problem, defined by the environment, which has not } \\
\text { yet been solved. Particularly, a number of recommendations have been proposed } \\
\text { for the challenges that EM practitioners face. Both the challenges and the } \\
\text { recommendations have been positioned within the frame of BITA using the } \\
\text { Strategic Alignment Model (SAM), which was a way to "package" the findings. } \\
\text { To answer the question, "What are the new and interesting contributions?", we } \\
\text { can claim that from a practical point of view, the identified EM challenges and } \\
\text { recommendations for each of the alignment perspectives can provide support for } \\
\text { EM practitioners that use EM in order to achieve BITA. From an academic point } \\
\text { of view, this study contributes to the BITA and EM domains by positioning EM } \\
\text { in the context of BITA, since it provides a conceptual definition of the } \\
\text { applicability of EM for BITA that has not been presented so far. }\end{array}$ \\
\hline $\begin{array}{l}\text { 5. Research rigor. This } \\
\text { guideline points out the fact } \\
\text { that design-science research } \\
\text { relies on the application of } \\
\text { rigorous methods in both the } \\
\text { construction and evaluation } \\
\text { of the design artifact. }\end{array}$ & $\begin{array}{l}\text { Rigor is derived from the effective usage of the knowledge base, including } \\
\text { both theoretical foundations and research methodologies. The generation and } \\
\text { validation of knowledge has been achieved through empirical, external } \\
\text { theoretical, and internal knowledge grounding [21]. The methods used in the } \\
\text { construction and evaluation of the design artifact are literature study (systematic } \\
\text { and focused), and interview (see description in Sections } 2.1 \text { and 2.2). The } \\
\text { application of systematic and focused literature reviews allowed us to use the }\end{array}$ \\
\hline
\end{tabular}




\begin{tabular}{|c|c|}
\hline Guidelines & How it is addressed in this study \\
\hline & $\begin{array}{l}\text { resources of the research team efficiently. That is, it allowed us to focus on the } \\
\text { existing theories thoroughly at the beginning of the research process and then to } \\
\text { focus on the empirical work, complimented by the focused literature reviews in } \\
\text { the later stages. Two rounds of interviews were conducted to enable the iterative } \\
\text { refinement of the EM-for-BITA framework. Working iteratively with the } \\
\text { framework, by using a combination of interview and literature review } \\
\text { methodologies in each iteration, allowed us to carry out the study in a structured } \\
\text { way and enabled the generation of the research results in a rigorous manner. }\end{array}$ \\
\hline $\begin{array}{l}\text { 6. Design as a search } \\
\text { process. This guideline } \\
\text { highlights the need to utilize } \\
\text { available means when } \\
\text { developing an effective } \\
\text { artifact in order to achieve } \\
\text { desired results and satisfy } \\
\text { laws in the problem } \\
\text { environment. }\end{array}$ & $\begin{array}{l}\text { Designing the EM-for-BITA framework was indeed a search process. Its aim } \\
\text { was to position EM into the context of BITA and to acquire practical knowledge, } \\
\text { regarding the application of EM, to bridge the gap between business and IT } \\
\text { within an enterprise. The development of the framework was achieved in three } \\
\text { iterations that shifted between investigating the existing literature and practice. }\end{array}$ \\
\hline $\begin{array}{l}\text { 7. Communication of } \\
\text { research. This guideline } \\
\text { demonstrates the importance } \\
\text { of the effective presentation } \\
\text { of design-science research to } \\
\text { both technology-oriented as } \\
\text { well as management- } \\
\text { oriented audiences. }\end{array}$ & $\begin{array}{l}\text { A number of presentations and reflective discussions of research results took } \\
\text { place as the research progressed. These provided constructive comments and } \\
\text { feedback from both research and practical points of views. Together, they helped } \\
\text { to increase the quality of the designed artifact. The presentations and discussions } \\
\text { took place at international conferences and workshops that specifically focused on } \\
\text { the EM and BITA domains - The Practice of Enterprise Modelling }(2012,2015) \\
\text { and the Workshop on Business and IT Alignment }(2012,2014) \text {. }\end{array}$ \\
\hline
\end{tabular}

\section{Theoretical Foundation}

This Section presents the theoretical foundation of the study. First, a general description and relevant theories of the BITA domain are introduced in Section 3.1. Thereafter, the important theories of the EM domain are presented in Section 3.2.

\subsection{Business and IT Alignment and its Dimensions}

One of the key factors for the success of an enterprise is the alignment between its business and IT dimensions. The importance of business and IT alignment is recognized and discussed by both academics and practitioners [1]. The number of studies has shown that alignment has a positive influence on IS effectiveness, increases business profitability, enhances the perceived levels of IT business values, supports IT use for competitive advantage and positively affects organizational performance [3].

The challenge of business and IT alignment is not new, as it arose from the use of information systems in organizations. There are two conceptual views of BITA. One view is that it is a process, i.e., a set of activities that should be undertaken. The second view is that it is a state, i.e., the amount of alignment [4]. The first view implies that BITA is an ongoing process which requires specific IT management capabilities, includes specific actions and has distinct patterns over time [4]. The second view implies that it is a state, for which it is possible to identify antecedents, measures, and outcomes.

BITA as a state is often criticized for being a "fuzzy" target, since, according to Silvius [26], practitioners often face an ambiguity: what exactly in the business should be aligned with IT? If the focus is on a strategic alignment, the suggestion would be a business strategy. However, in practice, a business strategy is often an unclear target, since strategy provides a direction, not a final destination. In the current literature, significant attention is given to strategic alignment. This refers to the degree to which the business strategy and plans, and the IT strategy and plans, complement each other [4]. The framework introduced in [3] defines three generic dimensions of 
BITA: human, social and intellectual dimensions. One of the most cited alignment frameworks is the Strategic Alignment Model (SAM) presented by Henderson and Venkatraman [27]. This model defines alignment as the degree of fit and integration between four elements: business strategy, IT strategy, business infrastructure, and IS infrastructure. The multivariate alignment of SAM's main elements includes six alignment perspectives: (1) strategic fit on business side - the alignment of business strategy and business structure; (2) strategic fit on IT side - the alignment of IT strategy and IT structure; (3) strategic integration - the alignment of business and IT strategies; (4) functional integration - the alignment of business and IT structures; (5) automation - cross-domain perspective that implies the alignment of business strategy and IT structure; (6) linkage - cross-domain perspective that implies the alignment of IT strategy and business structure. According to [27], the simplest and most straightforward approach to achieve BITA is to consider all combinations of any two domains of SAM. This, however, might be difficult when internal inconsistencies occur (e.g., when only considering external issues of business and IT strategies without considering internal organizational domains). In addition, considering all six bivariate combinations might be redundant. Therefore, in this study, we consider four key perspectives of the SAM model: the strategic fit on the IT side, the strategic fit on the business side, the strategic integration and the functional integration. These four dimensions connect four key elements of the SAM framework, which serve as an essence for most of the known alignment frameworks, providing a suitable frame for the purpose of our study.

Existing theories and models introduce a number of alignment dimensions. SAM describes three levels within an enterprise at which alignment occurs and which need to be considered: (1) the strategic level - IT and business strategy level; (2) the operational level - organizational and IT infrastructure and processes, or business and IT structure; (3) the cross-domain level connecting the strategic and operational levels [3]. Ross, et al. [28] distinguish between three IT assets: (1) the human asset; (2) the relationship asset; (3) the technology asset. The human asset deals with technical skills, business understanding of IT staff, and problem solving orientation comprising all the necessary facets to form a high-performing IT unit. The technology asset implies technical platforms and databases, and covers technology architecture as well as data and platform standards. The relationship asset is grounded in IT and business unit management sharing the risk and responsibility for the effective application of IT within an enterprise. Melville, et al. [29] differentiate between (1) human IT resources, (2) technological IT resources, and (3) complementary organizational resources. Human IT resources comprise technical skills (programming, systems integration, database development, etc.) and managerial skills (collaboration with business units and external organizations, project planning, etc.). Technological IT resources include infrastructure (shared technology including IT services across the enterprise) and business applications (employ the infrastructure, e.g., purchasing, sales, etc.). Organizational resources refer to resources that are complementary to IT, including non-IT physical resources and non-IT human resources. The essence is that these resources have to be combined in order to generate beneficial outcomes. Schlosser, et al. [3] propose a model that distinguishes between the organizational level on the one hand, and the nature of alignment on the other. A model that they propose includes three horizontal organizational layers (strategic, cross-domain, operational) and three vertical dimensions regarding the content of alignment (human, social, intellectual). The human dimension includes business skills and knowledge of IT executives; IT skills and knowledge of business executives; leadership skills of business and IT executives; managerial capabilities of business and IT executives, and other issues. Such issues, as shared understanding, mutual trust and respect, cultural fit, work relationships, informal structures between business and IT executives and regular employees, contribute to the social dimension. The intellectual dimension includes the alignment of business and IT strategy and plans; IT architecture alignment; IT standards and platforms alignment; alignment of business and IT structures (rights and roles, reporting, committees, formal meetings, centralization); IT project portfolio alignment; shared applications; IT infrastructure alignment; IT project 
alignment; alignment of IS and processes; alignment of business and IT structures (rights and roles, reporting, formal meetings); IT services alignment; procedures/workflow alignment.

\subsection{Enterprise Modeling - the Process and the Intentions}

There is a clear need to capture both organizational (business) and technological issues during the design and implementation of enterprise IS [30]. Moreover, capturing these dimensions in a valid and comprehensive way requires the involvement of a large number of stakeholders. In this respect, EM can serve as an effective practice. EM (sometimes also called business modeling, c.f. [31] is a practice that is employed to develop, obtain, and communicate enterprise knowledge, such as strategies, goals and requirements, to different stakeholders [31], [32].

EM is often used during the development or refinement of enterprise IS. Researchers pay significant attention to the applicability of EM for software requirements engineering [32], [33]. According to [20], EM is an activity where integrated and commonly shared models that describe different aspects of an enterprise, such as processes, business rules, concepts/information/data, vision/goals or actors, are created. A model plays an important role as a visual mapping of perceptions of the enterprise practice and thus fosters communication. It is a compact abstraction and thus allows coping with complexity. Models are usually based on shared concepts and consequently facilitate shared understanding [34].

According to [7], [8] and [34], the acts of collaboration, participation, and interaction among a large group of stakeholders are highly beneficial in the practice of EM, as they enable more effective and efficient model derivation and also increase the validity of models. The participative approach also implies the involvement of stakeholders in the modeling to improve the understanding of enterprise processes [7], [35]. One problem, which might occur here, is that the resulting enterprise models are often not formalized enough, thus possibly complicating their further application. Consequently, the role of the EM practitioner who leads this kind of EM effort becomes vital for the efficient creation and use of enterprise models [7], [12].

In terms of the modeling process itself, [19] proposes a model according to which the EM process includes three basic activities that are usually performed in sequential order, but in some cases are iterative (Figure 3). After starting the EM effort, the EM practitioner, often together with the domain experts, needs to analyze what information should be collected in order to reach the goal of the modeling effort. Therefore, the first activity of EM is to collect information about the enterprise at hand.

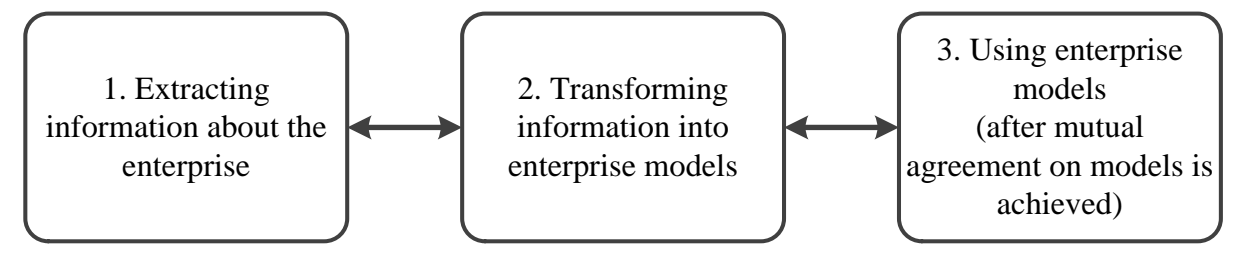

Figure 3. EM activities [19]

During participative EM, where domain experts play an important role, the main source of information is modeling sessions or workshops. During such sessions, the EM practitioner has a leading role in eliciting and integrating opinions about various aspects of the enterprise. The ability of the EM practitioner to facilitate this process is crucial, in order to extract the necessary information and then transform it into enterprise models (activity 2 in Figure 3). Models are created during modeling sessions together with domain experts to make sure that existing viewpoints are considered and consolidated. A common practice is to iterate between the first and second activity several times when creating models, to ensure that all the required information has been captured and documented. It is important to emphasize that the documentation of models is a continuous process which will proceed until a common agreement on the created models is achieved among the involved participants. Various challenges are 
specific for all three activities of EM. It is crucial that the stakeholders come on agreement on the resulting enterprise models in order to use them for any purpose (activity 3 in Figure 3).

Apart from the development or refinement of an enterprise IS, EM can be used to create shared domain knowledge [10], [36], [37]. Both purposes play an important role in BITA, although the results of using EM depend on the reason for EM effort in a particular case. In [36], a hierarchy of EM intentions is presented (Figure 4); it indicates the possible reasons for using EM. In addition, it has been further refined in [38]. This model has also been used to generate the EM framework presented in this article.

The hierarchy of EM intentions differentiates between three high-level intentions. The first one deals with ensuring the quality of the business, and primarily focuses on two issues: (1.1) ensuring the acceptance of business decisions by committing the stakeholders to the decisions made, and (1.2) maintaining and sharing knowledge about the business, its vision, and the way it operates. With respect to knowledge sharing, EM plays an important role, since it provides a multifaceted map of the business that functions as a communication platform between stakeholders. The second EM intention deals with developing the business, which is one of the most common intentions of EM. As such, EM can be used in the early stages of IS development to effectively gather business needs and high-level requirements. Developing the business might include (2.1) refining the business vision and strategies, (2.2) redesigning business operations, and (2.3) enhancing the information support systems.

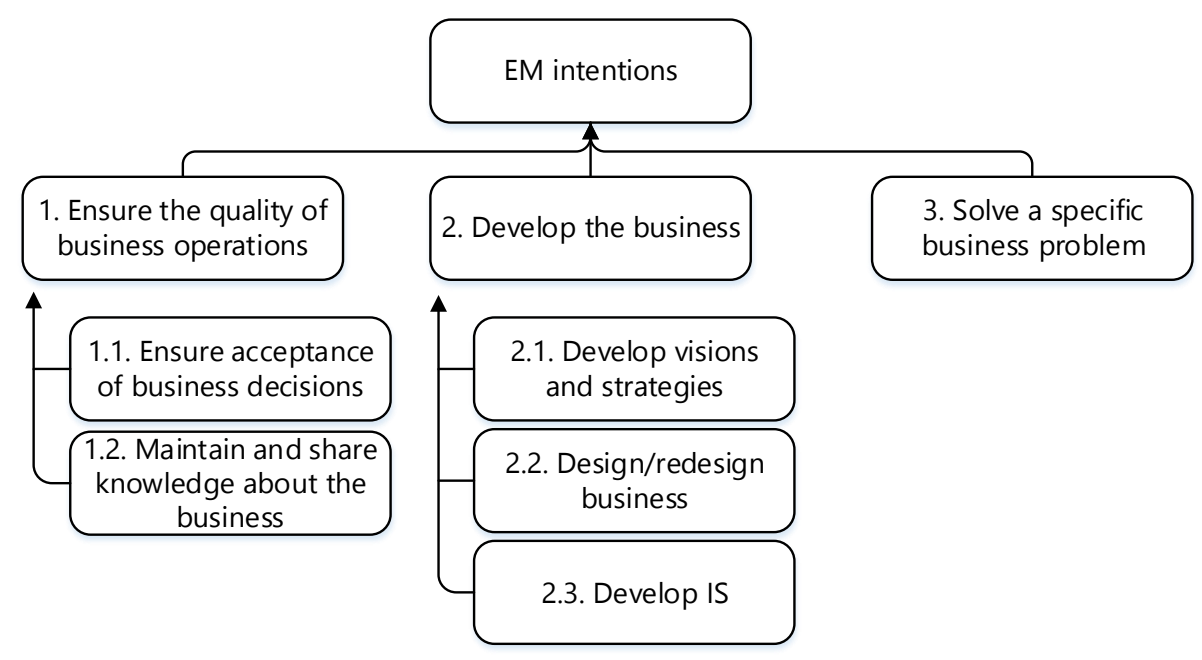

Figure 4. The main elements of the EM intentions hierarchy, adapted from [36]

The third top-level intention in the hierarchy deals with using EM as a problem-solving tool. As such, EM is only used to support the discussion among the stakeholders who are trying to analyze a specific problem. In such cases, EM can be applied to capture, delimit, and analyze the initial problem situation, and to decide on further actions. An intention of an EM initiative can affect various perspectives of BITA [39].

\section{The EM-for-BITA Framework}

The EM-for-BITA framework structures the EM challenges and recommendations, with regard to the position of EM in the context of BITA. The positioning of EM in the context of BITA is presented in Section 4.1, while the challenges specific to EM intentions are outlined in Section 4.2. Finally, the EM challenges and recommendations relevant to BITA are discussed in detail in Section 4.3. 


\subsection{Positioning of EM in the Context of BITA}

In order to position EM in the context of BITA, the EM intentions (Figure 4) are positioned in the SAM framework, which is represented in Figure 5. Since the positioning is supported by literature studies and interviews, the reasoning provided below is illustrated with interview quotations.

According to the interview respondents, EM is often used to create a multidimensional picture of the business and provide a common platform for communication between stakeholders. The commitment of stakeholders to make business decisions is one of the critical factors that facilitates the achievement of successful, high quality business operations.

\section{EM intention 1.1: Ensure acceptance of business decisions}

EM, particularly the participative approach, helps reveal and discuss different opinions about the business, which in turn enables a consensus to be found. The communication between stakeholders during EM sessions motivates them to commit to and carry out the business decisions they have discussed.

"The owner of the created model should be committed to applying and realizing it in the business." (Respondent 2-1)

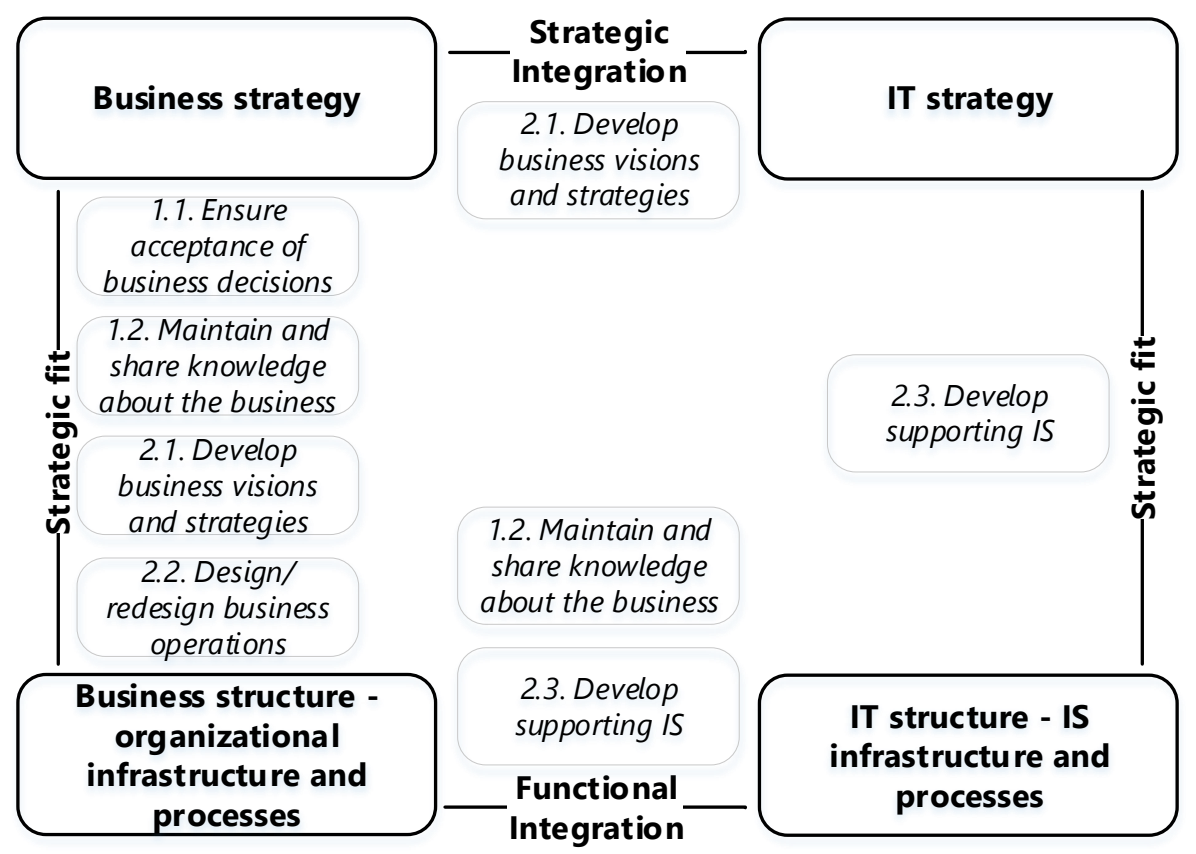

Figure 5. Positioning of EM intension in SAM

The enterprise models created serve as documented instructions for further implementation, which enables a strategic fit on the business side, since it allows stakeholders to improve the way business operates coherently with existing business strategy.

\section{EM intention 1.2: Maintain and share knowledge about the business}

Keeping employees informed about how the business operations are carried out and about the existing business vision and strategies is an important step to ensure the quality of the business. This kind of information is important for employees who need to have a clear understanding of the way the business works, the types of infrastructure that support it, as well as the vision and strategies that determine it.

"If you would like to share knowledge about business operations then EM, i.e. creating models together during particularly EM workshops, is an excellent way to do that!" (Respondent 2-4) 
Therefore, using EM to maintain and share knowledge about the business can contribute to BITA from two perspectives; it facilitates the strategic fit on the business side (the alignment of business strategy and business structure) and the functional integration (the alignment of business and IT structures).

In addition, the interviews revealed that EM is also commonly used for business development. This kind of development often entails changes in the business, for example, changes that are required to achieve the visions and objectives of an enterprise. Therefore, developing the business can entail using one or several of the following intentions.

\section{EM intention 2.1: Developing business visions and strategies}

Using EM to develop a business vision and strategies potentially enables strategic integration, i.e., the alignment of business and IT strategy, since, in such a case, EM is used as a tool to clarify and document business and IT strategies for an enterprise.

"It is quite time-consuming to create and communicate a vision and strategy. It is especially tricky to really make people understand and accept vision and strategies. The way to approach it is EM workshops." (Respondent 2-1)

An articulated and documented vision and strategy can then be discussed, refined and referred to, if needed. In some cases, clearly modeled and documented visions and strategies can help people to actually follow them in their daily work, which facilitates strategic fit on the business side. However, a similar effect for strategic fit on the IT side was not indicated in the interview data.

"Good visualization (a model) of business visions and strategies might work as a self-playing piano, since there will be no need for instructions to make people follow these visions and strategies in day-to-day operations. " (Respondent 2-1)

\section{EM intention 2.2: Redesigning business operations}

Sometimes organizations decide to reorient their business processes, which implies restructuring or redesigning business operations. For this purpose, several business process models are usually created and used. In addition, the existing vision and business strategy should be actively consulted.

"Often a company would like to pick up some opportunities on the market. In some cases, the board should plan if the company should enter another market. In other cases - the board should decide if the company should start producing another type of product. In both cases, we start EM by going through the vision and strategy. Based on that, it is possible to set goals for new things." (Respondent 2-2)

Using EM for this purpose enables a strategic fit on the business side, i.e., the alignment of business strategy and business structure.

\section{EM intention 2.3: Developing the supporting IS}

In many cases, EM is used for IS development. Using EM for this purpose provides an illustration of the as-is state of the business, which possibly includes a description of the business processes. In other words, EM provides a clear picture of how the business operates, which then serves as a basis for the development of the required IS.

"I have used EM a lot to identify the need for some kind of IT solution. When such a need exists, I have to create a functionality description based on business processes. Based on that I can see possible business use cases." (Respondent 2-3)

"You need to visualize IS - the parts of it that are useful and those parts which are not useful. Then it can be possible to take actions regarding those which are not useful anymore." (Respondent 2-1)

"We start by creating process models. After that we add a resource layer, where we can indicate the main areas for setting demands on the new IS." (Respondent 2-2) 
"Mostly you use enterprise models to show smarter ways of working that the enterprise can realize. Often implementation of a new IT system is one way of fulfilling these changes." (Respondent 2-4)

Thus, using EM for IS development enables functional integration (the alignment of business and IT structures) and strategic fit on the IT side (the alignment of IT strategy and IT structure). However, the interviews did not clearly reveal EM applicability for cross-functional alignment of IT strategy with business structure, or business strategy with IT structure.

EM can also be helpful in capturing, delimiting, and analyzing some kind of problematic situation, which then provides a basis for decision-making on an action required to solve a problem. Problematic situations can include, for instance, a flaw in enterprise operations or the inefficient distribution of roles and responsibilities among staff. In such cases, EM is mainly used as a communication tool. Enterprise models are used to document the problem at hand and are not meant to be used for further development work.

"In many cases, the problems that a company has in operations are in fact symptoms, so it is necessary to first identify the root of the problems." (Respondent 2-2)

This scenario often implies one of the situations described above (using EM to ensure the quality of the business operation or using EM to develop the business), and the use of EM for such does not directly influence BITA.

"EM workshops are an excellent way of sharing knowledge about a business and the way it operates. But if knowledge sharing is the only purpose of using EM then it is quite an expensive way to go!" (Respondent 2-4)

The findings regarding shared domain knowledge correspond, to some extent, to the results presented by Maharaj and Brown [40]. They demonstrate that shared domain knowledge positively influences the strategic characteristics of information system planning and the alignment between business and IT. Specifically, they claim that high levels of rationality in strategic information system planning positively influence the intellectual dimension of alignment, while IT manager participation in business planning influences the social dimension of alignment.

\subsection{EM Intentions and Corresponding Challenges}

Table 2 presents the intentions of EM use and the challenges [36] that are specific for each of them. The interviews reveal that reusing enterprise models, dealing with the backgrounds, knowledge and interpretations of diverse stakeholders, as well as presenting relevant information in an understandable way, constitute the relevant challenges for both groups of EM intentions. The in time discussion of technical solutions is related to using the enterprise model to develop the business. This challenge is not specific to the situations that require knowledge sharing or decision-making support, as it is mainly related to situations that require implementing specific IS/IT solutions.

Table 2. EM intentions and identified challenges

\begin{tabular}{|c|c|c|c|c|c|}
\hline General Purpose & \multicolumn{3}{|c|}{ To develop the business } & \multicolumn{2}{|c|}{ To ensure the quality of the business } \\
\hline Specific purpose & $\begin{array}{c}\text { Developing } \\
\text { business } \\
\text { vision or } \\
\text { strategy }\end{array}$ & $\begin{array}{l}\text { Redesigning } \\
\text { business } \\
\text { operations }\end{array}$ & $\begin{array}{c}\text { Developing } \\
\text { supporting } \\
\text { IS }\end{array}$ & $\begin{array}{c}\text { Maintain and } \\
\text { share } \\
\text { knowledge } \\
\text { about the } \\
\text { business }\end{array}$ & $\begin{array}{c}\text { Ensure acceptance of } \\
\text { business decisions }\end{array}$ \\
\hline \multirow{4}{*}{ Challenge } & \multicolumn{3}{|c|}{ 1. Timely discussion of technical solutions } & & \\
\hline & \multicolumn{3}{|c|}{ 2. Reuse of enterprise models } & & \\
\hline & \multicolumn{5}{|c|}{ 3. Dealing with diverse backgrounds, knowledge and interpretations } \\
\hline & \multicolumn{5}{|c|}{ 4. Presenting relevant information in an understandable way } \\
\hline
\end{tabular}


The challenges have been identified on the basis of the methodological base used in the study: the literature reviews and interviews. With regard to the challenges for each of the EM intentions, we could position them within the frame of BITA, particularly by using the model in Figure 5 and the correspondences in Table 2.

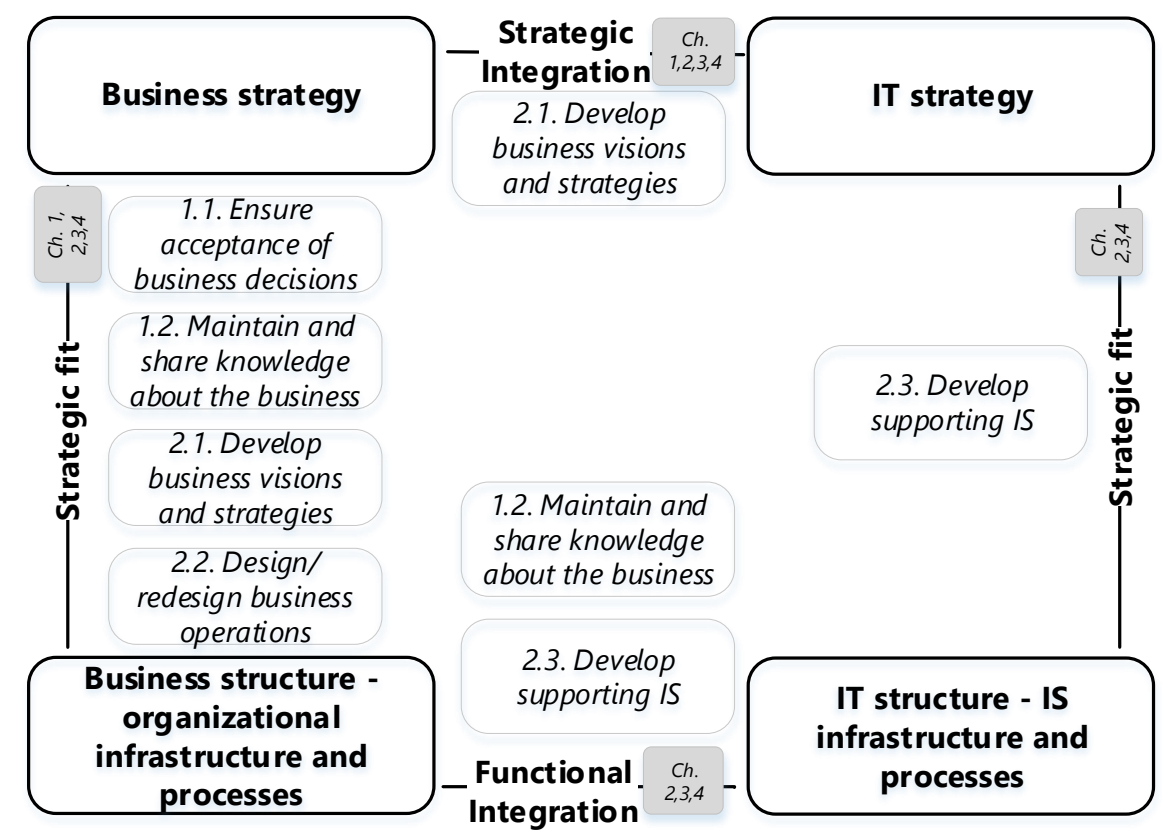

Figure 6. The EM-for-BITA framework (Ch-challenge in Table 1)

\subsection{Challenges and Recommendations}

The positioning of EM intentions in the context of BITA is presented in Figure 6, while the challenges (numbered 1-4) and recommendations are introduced in detail in Table 3. This Section also includes illustrative quotes from the interviews.

Table 3. EM challenges and recommendations relevant for the context of BITA

\begin{tabular}{|c|l|}
\hline Challenges & Recommendations \\
\hline $\begin{array}{l}\text { 1. Timely discussion of technical } \\
\text { solutions }\end{array}$ & $\begin{array}{l}\text { - Start modeling with a group of participants who have extensive } \\
\text { domain knowledge of problematic areas. } \\
\text { - Make sure that IT experts are involved in the process only after } \\
\text { the key areas have been identified and a general understanding of } \\
\text { what should be changed has been gained. }\end{array}$ \\
\hline 2. Reuse of enterprise models & $\begin{array}{l}\text { - Make sure the existing models are maintained in a repository and } \\
\text { kept up to date. } \\
\text { - The benefit of maintaining models should be clarified for the } \\
\text { enterprise management. }\end{array}$ \\
\hline knowledge and interpretations & $\begin{array}{l}\text { - Provide the participants with a brief reminder of the purpose of } \\
\text { the models being presented and a summary of the notation. } \\
\text { - When models are used as a basis for explanation and discussions, } \\
\text { the diverse backgrounds and knowledge of the stakeholders } \\
\text { involved should be considered and consolidated. }\end{array}$ \\
\hline $\begin{array}{l}\text { 4. Presenting relevant information in an } \\
\text { understandable way }\end{array}$ & $\begin{array}{l}\text { Use the benefit of a good visualization when applying models for } \\
\text { different purposes. } \\
\text { - Make sure the target audience can understand the models. }\end{array}$ \\
\hline
\end{tabular}




\section{Timely discussion of technical solutions}

During EM, there is a tendency to involve stakeholders with technical knowledge and expertise in the discussion process quite early. This can divert the discussions and create the risk of becoming focused on implementation details instead of discussing alternative solutions from the business perspective. The respondents highlight the inclination of IT specialists to take over the analysis as soon as they become involved in the modeling sessions. Therefore, it is important to prevent technical specialists from dominating the modeling sessions.

"In many cases, IT representatives want to take over the analysis too early. First experts from operations should make models that explain how operations are run (process models, concept model, etc.). If that is ready, then we can start the dialogue with IT representatives." (Respondent 2-2)

"It is hard to get beyond the discussion of particular IT solutions. People representing different parts of the business end up talking about IT solutions. It is really hard for people to say what they want to achieve in the business, and only after this look at what type of IT support is needed." (Respondent 2-3)

The analysis of the interviews reveals that EM practitioners recommend that a smaller group with extensive domain knowledge should start the modeling efforts and identify key areas for continuing work. The analysis also indicates and recommends that people with technical domain knowledge (IT experts) should not become involved until the key areas and problematic issues have been identified. Thereafter, the EM effort can proceed and focus on how to deal with these key areas, which could then initiate the involvement of IT experts.

"It is good to have technical details, but not before good quality enterprise models are ready. This is the best basis which sets demands for the IT." (Respondent 2-2)

This challenge is typical for scenarios where EM is used for the following intentions: (2.1) develop business vision and strategies, (2.2) redesign business operations, and (2.3) develop the supporting IS.

Recommendations:

- Start modeling with a group of participants who have extensive domain knowledge of problematic areas.

- Make sure that IT experts only become involved in the process after the key areas have been identified and a general understanding of what should be changed has been gained.

\section{Reuse of enterprise models}

This challenge refers to the fact that enterprise models are used only once. While this is highly inefficient, it is, unfortunately, a common practice in many cases.

"Resulting enterprise models might be hard to reuse. They can be too specific or incomplete, since their purpose is to be used to develop one particular IT system." (Respondent 2-4)

It requires considerable effort to ensure the continuous value of enterprise models over time. However, this could be dealt with by having an appointed person responsible for model maintenance and reuse, and establishing model repositories. The respondents emphasized the importance of repositories for the storage and maintenance of enterprise models. Such model maintenance is an important task, due to the dynamic nature of today's business environment, especially if an enterprise is captured and described in models that represent different parts and states of the enterprise. The reuse of enterprise models from previous modeling projects can be facilitated by adopting a restricted set of notation rules for modeling, covering methods and tools. 4)

"Explain to enterprise management what the value of model maintenance is!" (Respondent 2- 
"What is really needed is a repository that is used in the whole company, so that all new models can be related to old ones." (Respondent 2-4)

"For one company (sometimes for a business unit) you need to select a modeling technique, notation and tool to document and store models and put them into place. Then you can use enterprise models efficiently." (Respondent 2-4)

This challenge is relevant when EM is used to: (1.1) ensure the acceptance of business decisions by committing the stakeholders to the decisions made, (1.2) maintain and share knowledge about the business, its vision, and the way it operates, (2.1) develop business visions and strategies, (2.2) redesign business operations, and (2.3) develop the information systems support.

Recommendations:

- Make sure the existing models are maintained in a repository and that they are kept up to date.

- The benefit of models maintenance should be clarified for enterprise management.

\section{Dealing with diverse backgrounds, knowledge and interpretations}

Stakeholders that are involved in EM projects usually have different backgrounds and knowledge. For example, the skills of people in administration might differ from those that work in operations. This means that different groups of stakeholders may have significantly different interpretations of a situation in the focus. Achieving consensus about different enterprise aspects is therefore crucial during any EM effort. Hence, an EM practitioner has to consider the varied backgrounds of the stakeholders involved and to mediate between them in order to achieve consensus.

"If you have a workshop with people who have different backgrounds - people in finance, engineers, HR department, operations, product development - it means they look at reality differently. They often have different solutions depending on their preferences, backgrounds and knowledge." (Respondent 2-1)

The diverse backgrounds and interpretations of stakeholders can affect EM and restrict the use of models for any purpose. It is crucial to reach mutual understanding about the significance of different models before analyzing or implementing them. We therefore propose that the stakeholders are informed about what the models really represent in the enterprise. It can be useful to start with a brief explanation of the chosen modeling notation and/or method so that everyone's level of understanding is the same. The respondents emphasized that at this stage of using enterprise models (both to develop the business and to ensure the quality of the business), it is reasonable to keep such introductions quite short.

"Some participants might know how to read models, others might not. If you combine them, you have to do a "warm-up" - a short introduction of the method, so that everyone knows how to understand the models." (Respondent 2-2)

This challenge is relevant when EM is used to: (1.1) ensure the acceptance of business decisions by committing the stakeholders to the decisions made, (1.2) maintain and share knowledge about the business, its vision, and the way it operates, (2.1) develop the business vision and strategies, (2.2) redesign the business operations, and (2.3) develop the information systems support.

Recommendations:

- Provide the participants with a brief reminder of the purpose of the models being presented and a summary of the notation.

- When models are used as a basis for explanation and discussions, the diverse backgrounds and knowledge of the stakeholders involved should be considered and consolidated. 


\section{Presenting relevant information in an understandable way}

This challenge is closely related to the previous one. It emphasizes that EM practitioners need to present and provide relevant information to stakeholders and decision makers in a clear and understandable way. Since this can be a challenging task, due to the diversity of stakeholders' backgrounds, it requires that EM practitioners have relevant pedagogical and communication abilities.

\section{"It is hard to implement a model, since people first need to really understand it." (Respondent 2-1)}

"We are more likely to make decisions to act if we have a clear understanding of the subject matter. If we do not understand, then we resist making decisions. It is important to make the situation clear for key decision makers." (Respondent 2-2)

"If you are really into the model, you can fail to explain it. People are not here to learn about the model, but to solve the problem." (Respondent 2-3)

The interviews have shown that enterprise models are often used for decision-making. One suggestion in this context is to use illustrative models of satisfactory quality. The respondents also suggested that the models could be used as a basis for explanation. The main reason for this is because using models for explanatory purposes is more effective than using ordinary textual and verbal descriptions. However, textual and verbal explanations are still important, since models themselves also need to be explained. One aspect to keep in mind is to contextualize the explanations when the models are presented to the stakeholders.

"Use their language and talk their talk! Try to see, feel and understand their perspectives of the company and the environment. Then you can have a dialogue and communicate." (Respondent 2-1)

"Ask yourself: How would I communicate this to [management position X]? What is the suitable language? What is on the agenda? How do I translate things into the [management position X] situation?" (Respondent 2-1)

"You need to explain in other words!" (Respondent 2-3)

This challenge is relevant when EM is used to: (1.1) ensure the acceptance of business decisions by committing the stakeholders to the decisions made, (1.2) maintain and share knowledge about the business, its vision, and the way it operates, (2.1) develop the business vision and strategies, (2.2) redesign the business operations, and (2.3) develop the information systems support.

Recommendations:

- Use the benefit of a good visualization when applying models for different purposes.

- Make sure the target audience can understand the models.

\section{Discussion and Conclusions}

In the broad sense, this work investigates the role of EM in the context of BITA. In order to position EM in the context of BITA, the Strategic Alignment Model (SAM) was used as a frame. The positioning was carried out according to the intentions of EM use, since the effect of EM is highly dependent on the purpose of a particular EM effort. The resulting positioning suggests that EM can facilitate BITA in a number of ways. It contributes to strategic alignment and functional integration, and it also facilitates the fit between infrastructure and processes (both business and IS) and corresponding strategies. In addition to the positioning of EM in the context of BITA, this study identifies challenges that EM practitioners face when EM is used for BITA and proposes recommendations to deal with these challenges. These results are presented as the framework together with a set of EM challenges and recommendations that are specific for different alignment perspectives. The framework provides a detailed view of the implication of 
EM in the light of various alignment perspectives, which has so far not been described in a structured manner.

An important characteristic of the study is related to the aspects of EM under consideration. Most of the existing studies on EM challenges and recommendations focus on either (1) the collaborative nature of EM or (2) the required characteristics of created enterprise models, while only a few provide a combined view. The consideration of both aspects provides an opportunity to obtain a broader view of EM practice and to generate more comprehensive support for EM practitioners. This study considered both of these aspects. Various particulars of collaboration in EM were analyzed, when the extraction of information about the enterprise, in participative settings, and the creation and use of enterprise models were investigated. The desired characteristics of enterprise models were taken into account when we examined how extracted enterprise-related information is usually transformed into enterprise models and how created models can be used for various purposes. The result of this study, the EM-for-BITA framework, includes challenges and recommendations for the use of enterprise models for various intentions, which imply both of the aforementioned aspects.

The challenges and recommendations presented are valuable results from a practical point of view. The identified EM challenges and recommendations for each of the alignment perspectives can provide initial support for EM practitioners that use EM to achieve BITA. Our study used the knowledge foundations of the EM domain [11], [12], and the findings of our study confirm and compliment already existing knowledge. Some of the challenges identified cannot be solved completely due to technical issues. Although the proposed recommendations can help to manage these challenges, they should not be considered as instructions that alone can be used to solve the identified problems. The recommendations are based on the interview data, however, we regard their further validation in real EM projects as part of possible future work. In addition, it could be beneficial to apply the challenges and recommendations to specific BITA issues or case scenarios, in order to provide more detailed support for the use of EM for a certain BITA issue.

\section{References}

[1] A. J. G. Silvius, "Business and IT Alignment: What We Know and What We Don't Know," in 2009 International Conference on Information Management and Engineering, pp. 558-563, 2009. Available: https://doi.org/10.1109/ICIME.2009.125

[2] J. Luftman, “Assessing It/Business Alignment," Information Systems Management, vol. 20, pp. 9-15, September 2003. Available: https://doi.org/10.1201/1078/43647.20.4.20030901/77287.2

[3] F. Schlosser, H.-T. Wagner and T. Coltman, "Reconsidering the Dimensions of Business-IT Alignment," in Proceedings of the 2012 45th Hawaii International Conference on System Sciences, 2012. Available: https://doi.org/10.1109/HICSS.2012.497

[4] Y. E. Chan and B. H. Reich, "IT alignment: what have we learned?" Journal of Information technology, vol. 22, pp. 297-315, 2007. Available: https://doi.org/10.1057/palgrave.jit.2000109

[5] J. O. Vargas, "A Framework of Practices Influencing IS/Business Alignment and IT Governance," Doctoral thesis, School of Information Systems, Computing and Mathematics in Brunel University, 2011.

[6] H. Jonkers, M. Lankhorst, R. Van Buuren, S. Hoppenbrouwers, M. Bonsangue and L. Van Der Torre, "Concepts for modeling enterprise architectures," International Journal of Cooperative Information Systems, vol. 13, pp. 257-287, 2004. Available: https://doi.org/10.1142/S0218843004000985

[7] K. Sandkuhl, J. Stirna, A. Persson and M. Wiotzki, Enterprise Modeling: Tackling Business Challenges with the 4EM Method. Springer, 2014. Available: https://doi.org/10.1007/978-3-662-43725-4

[8] J. Stirna and A. Persson, "Anti-patterns as a means of focusing on critical quality aspects in enterprise modeling," in Enterprise, Business-Process and Information Systems Modeling, Springer, pp. 407-418, 2009. Available: https://doi.org/10.1007/978-3-642-01862-6_33 
[9] G. S. Kearns and A. L. Lederer, "A resource- based view of strategic IT alignment: how knowledge sharing creates competitive advantage," Decision sciences, vol. 34, pp. 1-29, 2003. Available: https://doi.org/10.1111/1540-5915.02289

[10] B. H. Reich and I. Benbasat, "Factors that influence the social dimension of alignment between business and information technology objectives," MIS quarterly, pp. 81-113, 2000. Available: https://doi.org/10.2307/3250980

[11] J. Stirna and A. Persson, "Purpose Driven Competency Planning for Enterprise Modeling Projects," in Advanced Information Systems Engineering: 24th International Conference, CAiSE 2012, Gdansk, Poland, June 25-29, 2012. Proceedings, J. Ralyté, X. Franch, S. Brinkkemper, and S. Wrycza, Eds., ed Berlin, Heidelberg: Springer Berlin Heidelberg, pp. 662-677, $2012 . \quad$ Available: https://doi.org/10.1007/978-3-642-31095-9_43

[12] M. Rosemann, A. Hjalmarsson, M. Lind and J. Recker, Four facets of a process modeling facilitator, 2011.

[13] S. Gregor, D. Hart and N. Martin, "Enterprise architectures: enablers of business strategy and IS/IT alignment in government," Information Technology \& People, vol. 20, pp. 96-120, 2007. Available: https://doi.org/10.1108/09593840710758031

[14] A. Wegmann, G. Regev, I. Rychkova, L.-S. Lê and P. Julia, "Business and IT alignment with SEAM for enterprise architecture," in Enterprise Distributed Object Computing Conference, 2007. EDOC 2007. 11th IEEE International, pp. 111-111, 2007. Available: https://doi.org/10.1109/EDOC.2007.54

[15] U. Seigerroth, "Enterprise Modeling and Enterprise Architecture: the constituents of transformation and alignment of Business and IT," International Journal of IT/Business Alignment and Governance (IJITBAG), vol. 2, pp. 16-34, 2011. Available: https://doi.org/10.4018/jitbag.2011010102

[16] F. Christiner, B. Lantow, K. Sandkuhl, and M. Wißotzki, "Multi-dimensional visualization in enterprise modeling," in Business Information Systems Workshops, pp. 139-152, 2012. Available: https://doi.org/10.1007/978-3-642-34228-8_14

[17] A. R. Hevner, S. T. March, J. Park and S. Ram, "Design Science in Information Systems Research," Management Information Systems Quarterly, vol. 28, p. 6, 2004.

[18] J. Kaidalova, U. Seigerroth, T. Kaczmarek and N. Shilov, "Practical challenges of enterprise modeling in the light of business and it alignment," in IFIP Working Conference on The Practice of Enterprise Modeling, pp. 31-45, 2012. Available: https://doi.org/10.1007/978-3-642-34549-4_3

[19] J. Kaidalova, U. Siegerroth, E. Bukowska and N. Shilov, "Enterprise modeling for business and IT alignment: challenges and recommendations," International Journal of IT/Business Alignment and Governance (IJITBAG), vol. 5, pp. 44-69, 2014. Available: https://doi.org/10.4018/ijitbag.2014070103

[20] J. Stirna, A. Persson and K. Sandkuhl, "Participative enterprise modeling: experiences and recommendations," in International Conference on Advanced Information Systems Engineering, pp. 546-560, 2007. Available: https://doi.org/10.1007/978-3-540-72988-4_38

[21] G. Goldkuhl, The grounding of usable knowledge: An inquiry in the epistemology of action knowledge: CMTO, Linköpings universitet, 1999.

[22] B. Kitchenham, "Procedures for performing systematic reviews," Keele, UK, Keele University, vol. 33, pp. 126, 2004.

[23] J. Kaidalova, "Towards a definition of the role of enterprise modeling in the context of business and IT alignment," Licentiate, University of Skövde, Skövde, 2015.

[24] J. Luftman, B. Derksen, R. Dwivedi, M. Santana, H. S. Zadeh and E. Rigoni, "Influential IT management trends: an international study," Journal of Information Technology, vol. 30, pp. 293-305, 2015. Available: https://doi.org/10.1057/jit.2015.18

[25] A. Karlsen and A. L. Opdahl, Enterprise modeling practice in a turnaround project / Anniken Karlsen og Andreas L. Opdahl. xx\#, 2012.

[26] A. G. Silvius, "Business \& IT Alignment in theory and practice," in System Sciences, 2007. HICSS 2007. 40th Annual Hawaii International Conference on, pp. 211b-211b, $2007 . \quad$ Available: https://doi.org/10.1109/HICSS.2007.119

[27] J. C. Henderson and N. Venkatraman, "Strategic alignment: a model for organizational transformation through information technology," Transforming organizations, pp. 97-117, 1992. 
[28] J. W. Ross, C. M. Beath and D. L. Goodhue, "Develop long-term competitiveness through IT assets," Sloan management review, vol. 38, p. 31, 1996.

[29] N. Melville, K. Kraemer and V. Gurbaxani, "Review: Information technology and organizational performance: An integrative model of IT business value," MIS quarterly, vol. 28, pp. 283-322, 2004.

[30] C. F. Gibson, "IT-enabled business change: an approach to understanding and managing risk," 2004.

[31] M. Kirikova, "Explanatory capability of enterprise models," Data \& Knowledge Engineering, vol. 33, pp. 119136, 2000. Available: https://doi.org/10.1016/S0169-023X(99)00048-8

[32] A. Persson, Enterprise modelling in practice: situational factors and their influence on adopting a participative approach: Univ., 2001.

[33] C. Rolland and N. Prakash, "From conceptual modelling to requirements engineering," Annals of Software Engineering, vol. 10, p. 151, 2000. Available: https://doi.org/10.1023/A:1018939700514

[34] J. Barjis, "Collaborative, participative and interactive enterprise modeling," in International Conference on Enterprise Information Systems, pp. 651-662, 2009. Available: https://doi.org/10.1007/978-3-642-01347-8_54

[35] D. Rieu and M. Santorum, "A participative end-user modeling approach for business process requirements," in Enterprise, Business-Process and Information Systems Modeling, Springer, pp. 33-47, 2014. Available: https://doi.org/10.1007/978-3-662-43745-2_3

[36] A. Persson and J. Stirna, "Why enterprise modelling? an explorative study into current practice," in International Conference on Advanced Information Systems Engineering, pp. 465-468, 2001. Available: https://doi.org/10.1007/3-540-45341-5_31

[37] M. Lind and U. Seigerroth, "Team-based reconstruction for expanding organisational ability," Journal of the Operational Research Society, vol. 54, pp. 119-129, $2003 . \quad$ Available: https://doi.org/10.1057/palgrave.jors.2601474

[38] J. Bubenko Jr, A. Persson and J. Stirna, “An intentional perspective on enterprise modeling," in Intentional perspectives on information systems engineering, Springer, pp. 215-237, 2010. Available: https://doi.org/10.1007/978-3-642-12544-7_12

[39] J. Kaidalova, "Positioning Enterprise Modeling in the context of Business and IT alignment," in International Conference on Business Information Systems, pp. 202-213, $2014 . \quad$ Available: https://doi.org/10.1007/978-3-319-11460-6_18

[40] S. Maharaj and I. Brown, "The impact of shared domain knowledge on strategic information systems planning and alignment: original research," South African Journal of Information Management, vol. 17, pp. 1-12, 2015. Available: https://doi.org/10.4102/sajim.v17i1.608 